\title{
Dominação e Resistência na Escolarização Cristianizada na Amazônia
}

\author{
Raimundo Nonato de Pádua Câncio' \\ Sônia Maria da Silva Araújo"
}

'Universidade Federal do Tocantins (UFT), Palmas/TO - Brasil

"Universidade Federal do Pará (UFPA), Belém/PA - Brasil

RESUMO - Dominação e Resistência na Escolarização Cristianizada na Amazônia. O objetivo deste estudo é demonstrar como a escolarização cristianizada, mobilizada por missionários norte-americanos, foi apropriada pelos indígenas Waiwai da Aldeia Mapuera, estado do Pará, Amazônia brasileira. Metodologicamente, trata-se de um estudo de caso do tipo etnográfico realizado no Território Indígena Nhamundá-Mapuera/PA com professores e sujeitos indígenas. No plano teórico, a análise dos dados se inspira na teoria decolonial. Os resultados mostram que os Waiwai não aceitaram passivamente o processo imposto, não obstante compreenderem a escolarização como um valor irremediável. Práticas de dominação e resistência, contraditoriamente, foram sendo estabelecidas e hoje atuam como instrumental de sobrevivência.

Palavras-chave: Waiwai. Escolarização. Cristianização. Dominação. Resistência.

ABSTRACT - Domination and Resistance in Christianized Schooling in Amazon. The aim of this study is to demonstrate how Christianized schooling, mobilized by American missionaries, was appropriated by the Waiwai indigenous people from Aldeia Mapuera, state of Pará, in the Brazilian Amazon. Methodologically, this is an ethnographic case study carried out in the Indigenous Territory Nhamundá-Mapuera in Pará, with teachers and indigenous people. At the theoretical level, data analysis is inspired by decolonial theory. The results show that the Waiwai did not passively accept the imposed process, despite understanding schooling as an irremediable value. Practices of domination and resistance, contradictorily, were being established and today they act as instruments of survival.

Keywords: Waiwai. Schooling. Christianization. Domination. Resistance.

Educação \& Realidade, Porto Alegre, v. 46, n. 1, e106385, 2021.

http://dx.doi.org/10.1590/2175-6236106385 
Dominação e Resistência na Escolarização Cristianizada na Amazônia

\section{Introdução}

A história da escolarização do povo Waiwai, ocorrida na Aldeia Mapuera, e que apresentamos neste $\operatorname{artigo}^{1}$, é mais um exemplário de como ideias, conceitos e perspectivas ocidentais foram introduzidos nas mais diversas culturas colonizadas do mundo, transformadas em periféricas. Essa história, definida pelos estudiosos da teoria decolonial como um processo de dominação política e epistemológica, tenta esvaziar homens e mulheres de suas subjetividades, fazendo prevalecer uma forma de ser e de saber que os impede de avançar para além da independência política.

No caso específico dos Waiwai, como também ocorreu (e ainda ocorre) com grande parte das populações indígenas do mundo, qualificadas por anos pelo Ocidente europeu como desprovidas de cultura, a história não se processou sem resistência, muito pelo contrário. Como veremos, a dominação projetada pelos missionários protestantes estadunidenses entre os Waiwai, que os escolarizou pela cristianização, resultou em transformações sociais e linguísticas que, contraditoriamente, os instrumentalizou para articular estratégias e táticas de resistência.

Metodologicamente, trata-se de um estudo de caso do tipo etnográfico, realizado na Aldeia Mapuera, localizada no Território Indígena $(\mathrm{TI})^{2}$ Nhamundá-Mapuera, estado do Pará, Amazônia brasileira, cuja abordagem é qualitativa. O estudo de caso do tipo etnográfico possui suas bases de constituição na Antropologia e vem sendo utilizado pela pesquisa educacional e definido, conforme André (2008, p. 23), como uma "[...] adaptação da etnografia ao estudo de um caso educacional". Esclarece a autora que, na educação, a descrição densa deve ser do processo educativo e, para que o estudo seja reconhecido como etnográfico, é preciso que se enfatize o singular, o particular, seja ele uma pessoa, uma instituição, um programa inovador ou um grupo social (André, 2008).

Seguindo as orientações da etnografia, utilizamos, basicamente, a observação e o relato como técnicas de recolha de dados. As observações e o material iconográfico foram detalhadamente registrados em um diário de campo. Os relatos foram capturados por meio de gravação de áudio, realizada no transcurso da etnografia. Para este artigo, apresentamos fragmentos de transcrições de relatos de 08 (oito) interlocutores: 06 (seis) indígenas professores e 04 (quatro) indígenas não professores.Visando a preservação do anonimato de nossos interlocutores, identificamos ao longo do texto os indígenas professores como INDPROF 1, INDPROF 2, INDPROF 3, INDPROF 4, INDPROF 5 e INDPROF 6; e os indígenas não professores como IND 1 e IND 2.

O texto está organizado em duas diferentes seções, além da introdução e das considerações finais apresentadas. Na primeira seção, trazemos considerações acerca da formação social e linguística dos Waiwai da Aldeia Mapuera, destacando a complexidade da formação cultural desse povo e alguns aspectos da língua indígena na comunica- 
ção Waiwai. Na segunda seção, apresentamos e discutimos o processo de escolarização dos conhecimentos dos norte-americanos entre eles, dando destaque às irrupções e disputas em torno das condições de produção e manutenção dos conhecimentos.

\section{Formação Social e Linguística dos Waiwai da Aldeia Mapuera}

Os estudos sobre a formação cultural do povo indígena Waiwai registram que ele deriva de uma mistura de grupos étnicos originários Waiwai, Parukoto, Tarumã e Mawayana. Por isso, em determinado contexto, um Waiwai pode se autodenominar Parukoto, como fazem os Katuena, os Hixkaryana e os Xereu. Assim, a questão de saber quem são exatamente os povos Waiwai é complexa, tanto para os antropólogos quanto para os próprios indígenas (Howard, 1993, p. 230). O antropólogo dinamarquês Niels Fock, ao realizar pesquisa de campo entre esse povo nos anos 1954-1955, registrou a dificuldade de determinar o grupo devido à sua origem misturada. Todavia, segundo ele, os Waiwai são, do ponto de vista étnico, dominados pelos Parukoto, muito embora, “[...] do ponto de vista linguístico, pareçam independentes” (Fock, 1963, p. 9).

A grafia do termo Waiwai ${ }^{3}$ varia e também é registrada como Uaiuai pela literatura etnológica, cuja designação genérica faz referência a vários povos indígenas que se uniram em um dado momento histórico e hoje ocupam, no Brasil, uma extensa região que compreende o Sul da Guiana (rio Essequibo), o Leste do Estado de Roraima (rios Jatapu e Anauá) e o Noroeste do estado do Pará (rio Mapuera), na Amazônia setentrional, região onde a Serra Acaraí delimita a fronteira entre o Brasil e a Guiana. Fock (1963), que estudou a cultura Waiwai, esteve entre eles antes da presença missionária norte-americana, registrou que Waiwai foi um termo criado pelos Wapixana para designar um povo indígena que possuía a pele mais clara ${ }^{4}$. Na língua Wapixana, segundo o mesmo autor, Waiwai possui o mesmo significado de farinha branca ou tapio$c a^{5}$.

No Brasil, os Waiwai ocupam uma área que engloba três terras indígenas, a TI Waiwai (RR), no Sudoeste de Roraima; a TI NhamundáMapuera (AM/PA), no Noroeste do Pará e Norte do Amazonas; e a TI Trombetas-Mapuera (AM/RR/PA). Nesta última está localizada a Aldeia Mapuera (ou Yxamna), lócus de investigação deste estudo. Considerada a aldeia mãe, é banhada pelo rio Mapuera (Mapuera Yewku), um dos afluentes do rio Trombetas-PA. Os dados da FUNAI, de 2016, obtidos em Mapuera, indicam que só nesta aldeia viviam cerca de 1.062 indígenas, agrupados em famílias que residiam em aproximadamente cem casas.

A construção mais representativa dos Waiwai na Aldeia Mapuera é a Umaná, também chamada de casa grande, construída numa área estratégica não muito centralizada, na qual são realizadas as reuniões e as festas mais tradicionais da cultura Waiwai. Atualmente a Umaná tem abrigado os cultos evangélicos porque a Igreja (Kaan Mîm) foi demolida para a construção de um templo mais imponente. A Igreja em Mapuera, 
Dominação e Resistência na Escolarização Cristianizada na Amazônia

cuja construção inicial foi orientada pelos missionários norte-americanos, está localizada em um espaço bem mais estratégico que a Umaná.

No que se refere aos aspectos sociolinguísticos dos Waiwai da Aldeia Mapuera, é importante observar que são multilíngues, pois vivem em região de fronteira, ocupando territórios do Brasil e da Guiana de colonização inglesa. As experiências de contato dos Waiwai com outros povos indígenas e com os demais habitantes dos países em que circulam, possibilitou a eles que falassem, além de suas línguas originárias, as línguas de outros povos indígenas e, ainda, as línguas nacionais dos países fronteiriços da região.

Meira (2006, p. 160) explica que a família linguística Karib, da qual os Waiwai são originários, possui membros em vários países da região amazônica. Além do Brasil e dos países já citados, há línguas desta família também na Colômbia e na Venezuela. Conforme o autor, as línguas Karib estão mais centradas no Norte do rio Amazonas, ao contrário das línguas Tupi, encontradas, sobretudo, ao Sul do Amazonas. Destaca ainda que, antes da invasão da América, os povos desta família linguística ocupavam também as ilhas do Caribe. Com isso, podemos dizer que a distribuição atual das línguas Karib reflete trocas históricas decorrentes das relações entre as populações originárias e os invasores europeus.

Ainda segundo Meira (2006, p. 169), a classificação da família Karib apresenta vários pontos duvidosos. Para ele, há uma classificação provisória onde a língua Waiwai se apresenta ligada ao Grupo Parukotoano, do Ramo Guianense da família Karib. A classificação linguística e etnológica de Frikel (1958) também mostra que a bacia do rio Trombetas era (e ainda é) habitada quase que exclusivamente por povos Karib, embora ainda haja entre eles indígenas falantes de línguas Arawak, como os Mawayana e os Wapixana, por exemplo.

Frikel (1958, p. 25) explica ser bem provável que os nomes desses grupos (entre eles o Waiwai) não sejam autodenominações, mas estejam relacionados ao espaço social, às paisagens e aos rios da região em que vivem. O autor também deduz que os habitantes dessa região compartilham nomeações comuns, como as que possuem a terminação yana, que significa gente, moradores ou povo. Explica que derivações como essas podem ter surgido de nomes associados a lugares, como rio Cachorro (kachu), e à denominação do povo que habita o curso desse rio, os Kachuyana.

Como se trata de diversos povos, é necessário pensarmos no que os autores chamam de redes de relações e mudanças que atravessaram esses grupos ao longo do tempo e repercutiram no rompimento das $l i$ nhas fronteiriças que, de certa forma, poderiam delimitar as suas identidades. Daí dizer que a compreensão do quadro da distribuição espacial desses povos indígenas, considerando seus aspectos linguísticos e culturais, aponta para a necessidade de maiores estudos sobre os aspectos sociolinguísticos dos povos que viveram e ainda vivem na região denominada Baixo Amazonas. 
Desta forma, é importante considerar o processo histórico nas reflexões acerca da formação das palavras da língua waiwai, as trocas linguísticas, mas também é importante atentar, nessas relações, para as situações de contato linguístico e as consequências disso para os papeis sociais desempenhados nas relações com os interlocutores, principalmente para a dinâmica das interações sociais e processos culturais mediados pela linguagem. Podemos dizer então que a língua waiwai falada atualmente em Mapuera é atravessada por todas essas marcas, inclusive pelas marcas advindas da relação desses povos com falantes de língua inglesa e de língua portuguesa, o que pressupõe empréstimos linguísticos, influências entre línguas que entram em contato, o que requer estudos mais aprofundados.

Por meio do diálogo com o povo Waiwai, pudemos verificar que a língua waiwai falada na Aldeia Mapuera possui um conjunto significativo de vocábulos e expressões de origens diversas, o que refuta a ideia de pureza linguística entre eles (Câncio, 2017). Esses empréstimos lexicais podem ter ocorrido por diferentes razões: necessidade de um vocábulo para designar algo novo dentro da cultura; influência; empréstimo de expressões de uma língua, dentre outras.

Há empréstimos utilizados para designar objetos que não existiam entre eles antes do contato com os missionários norte-americanos. Como exemplo, citamos os termos para laranja e mamão: oranci e mamaya, em waiwai, ambos assimilados dos termos orange e papaya da língua inglesa (Câncio, 2017). Nestes dois termos podemos dizer que ocorreu a supressão de um segmento sonoro nas palavras, uma espécie de assimilação dos sons de língua diferente, não indígena, para a formação de uma nova palavra na língua indígena.

Há palavras em waiwai criadas para nomear um elemento ou um ser estranho a eles, pois algumas palavras utilizadas inicialmente pelos não indígenas naquele contexto não eram dotadas de significação para os indígenas, daí a necessidade de ser dado um novo nome. Como exemplo, podemos citar Kaan (Deus), criada para nomear um ser que era, até então, estranho a eles, pois não pertencia àquele campo semântico. Como observa Câncio (2017, p. 145), neste caso, não se trata exatamente de um estrangeirismo, mas de uma palavra criada na língua indígena para situar e nomear o deus do estrangeiro, o que configura o entrelugar da atual religiosidade e da cultura Waiwai.

Ao descrever os aspectos fonológicos da língua waiwai, Neil Hawkins (1952) fez uso do alfabeto fonético que representava à época a tradição norte-americana, onde o International Phonetic Alphabet (IPA) era menos usado nos trabalhos de descrição de línguas. Há, portanto, algumas diferenças na forma mais usual de representar os sons pelo IPA. Nessa direção, Acácio (2011) fez um estudo fonético-fonológico detalhado desta língua, considerando que, antes dela, as únicas pesquisas sobre a fonologia waiwai eram as de Neil Hawkins (1952) e Robert Hawkins (1998). Em 2002, o missionário linguista Robert Hawkins entregou ao povo Waiwai a Bíblia traduzida para a língua indígena (Souza, 2014, p. 86). 
Dominação e Resistência na Escolarização Cristianizada na Amazônia

Em situações de contato com falantes da língua portuguesa, os Waiwai precisam compreender algumas diferenças que há entre os sons desta língua e os da língua indígena. No que se refere ao português, eles foram ensinados a adaptar a pronúncia da palavra às regras da fonologia da língua waiwai. Esse entendimento e as adaptações necessárias exigem do falante indígena maior esforço, nem sempre bem aceitos pelos não indígenas, visto que o contato inicial entre as duas línguas lhes ocasiona alguns problemas. Muitas vezes a carência dessas adaptações nas falas dos Waiwai é compreendida como um erro para os falantes de português, ou seja, uma infração às convenções ortográficas da língua portuguesa, o que leva os indígenas a se sentirem constrangidos, como evidenciado em suas falas ${ }^{6}$ :

Os nossos alunos possuem muitos problemas. Por exemplo, em nossa língua temos vários sons. Nós trocamos o som do P da língua portuguesa pelo som do F, o som do L pelo R. Essas trocas dificultam muito a aprendizagem do português [...] é importante entender que nem todos gostam ou querem aprender português, há alunos que também gostam muito de matemática, e, quando chega o professor de português, muitos deles demonstram-se desinteressados. Então gostar ou não de português é algo individual, depende de cada um (Relato do INDPROF 2, 16/11/2016).

[...] alguns sons do português são diferentes dos sons da língua waiwai. Em português nós temos o som do L, mas esse som, em nossa língua, é substituído pelo som do R (rá). Não há o som (lá) em nossa língua. Não há também o som do G em nossa língua, aí nós substituímos pelo som do X (xi). Então nós temos sons diferentes, e isso faz com que eles tenham muitas dificuldades, até compreenderem isso. Eles têm muita dificuldade em Língua Portuguesa com relação ao significado de algumas palavras (Relato do INDPROF 6, 22/11/2016).

É muito frequente o rotacismo entre os indígenas que falam português. Como exemplo, podemos observar, de forma muito frequente, a troca da consoante [l] pela consoante [r] nas palavras, como em bolacha>buracha. Esse processo fonológico ${ }^{7}$ torna-se um fenômeno altamente estigmatizado nas cidades pelos não indígenas falantes de português, sendo um comportamento linguístico indesejável para eles. Quando ocorre o rotacismo, geralmente o falante indígena é avaliado negativamente, isto é, como um sujeito que fala mal o português por ser descuidado com a língua e o riso é a primeira manifestação dessa reprovação. Tal reação quase sempre está associada à visão estereotipada que as pessoas têm dos povos indígenas.

Entre os Waiwai da Aldeia Mapuera podemos dizer que o uso do português ainda é pouco recorrente, se considerarmos naquele contexto as outras línguas faladas. Outro aspecto importante é que raramente um Waiwai é monolíngue, pois a necessidade da comunicação com outros povos faz com que eles sempre aprendam outras línguas. Os mais 
idosos são na maioria multilíngues, pois falam, além da língua Waiwai e outras línguas indígenas, a língua portuguesa e a língua inglesa, tendo em vista que muitos deles vieram da Guiana (antiga Guiana Inglesa) para o Brasil em meados de 1940. A questão do multilinguismo entre eles pode ser observada nas falas que seguem:

Atualmente, nós utilizamos a língua waiwai, mas primeiro utilizávamos a língua antiga. Aí, quando viemos para a Aldeia Mapuera, falamos uma língua diferente. Vieram pra cá Mawayana, Hixkaryana, Tiriyó, Xerew, Kiyana, entre outros daqui. Portanto, várias etnias moravam aqui. Mas havia a língua waiwai, e nós passamos a aprender esta língua (Relato do INDPROF 3, 21/11/2016).

Aqui nós temos várias línguas, nós temos a língua geral, que é o Waiwai, a língua Mawayana, a Tunayana, a Wapixana e a Hixkaryana. São várias etnias, por isso que há várias línguas, mas muitas línguas são pouco faladas e outras já até se perderam (Relato do IND 1, 21/11/2016).

Os falantes de língua portuguesa na Aldeia Mapuera, deslocados da Guiana, são, hoje, na maioria adultos. Eles vieram para o território brasileiro ainda crianças, fundaram as suas aldeias e faziam expedições pelas cidades brasileiras, passando a ter contatos mais frequentes com os não indígenas. Alguns desses adultos são as atuais lideranças, o que lhes exige maior desenvoltura com o português e também lhes proporciona mais viagens às cidades. A língua franca, a mais falada em Mapuera, é a língua waiwai. Eles defendem a manutenção e o uso da língua indígena como quem defende o próprio território, como se pode verificar em seguida:

[...] a nossa primeira língua é o waiwai. Ela faz parte dos nossos costumes. Nós estamos acostumados a falar em língua indígena, falamos entre nós e as pessoas da comunidade. Não queremos perder esse costume, queremos preservar a nossa cultura e, para isso, nós mantemos a nossa língua waiwai no contato entre nós [...] (Relato do INDPROF 4, 27/06/2016).

Também é falada em Mapuera uma variedade do português, cuja aquisição ocorre em condições adversas, por indivíduos em sua maioria jovens. As limitações decorrentes do fato desses indígenas quando adultos e idosos não terem mais acesso a dispositivos que facilitem a aprendizagem do português, geram, em alguns deles, uma potencial resistência cultural à língua portuguesa, enfatizada no discurso em favor da manutenção da língua materna. Verificamos que a língua mais recorrente, inclusive na escola, é a língua waiwai.

\section{A Escolarização Cristianizada dos Waiwai Promovida por Missionários Norte-Americanos}

O geógrafo inglês Robert Schomburgk, o geólogo britânico Barrington Brown e o geógrafo francês Henri Coudreau foram os três 
Dominação e Resistência na Escolarização Cristianizada na Amazônia

viajantes que fizeram contato com os Waiwai no século XIX, segundo Schuler Zea (2010, p. 3-4), e registraram que entre esses povos indígenas já havia uma ampla rede de intercâmbios, que se estendia a outros grupos indígenas da região, por onde se dava a circulação de objetos, técnicas, rituais e pessoas. Howard (1993) comenta que havia nesse espaço da Amazônia brasileira uma relação de troca entre os indígenas que envolvia, inclusive, interações com outros povos das Guianas inglesa, holandesa e francesa, além da Venezuela.

Essa ampla rede de intercâmbio vai ocorrer em meio a um processo de colonialidade ${ }^{8}$ que se aprofunda a partir do século XIX ao se utilizar estratégias outras que não a perseguição e captura, mas a conversão religiosa, a pregação da fé cristã, que também alcançou povos de origem africana deslocados para a região do Alto Trombetas-PA, resultando na formação de vilas sob orientações religiosas. Em relação especificamente às áreas de fronteiras no Norte do Brasil, Souza (2006) explica que:

\begin{abstract}
Não havia uma organização missionária institucionalizada para a catequese das nações indígenas residentes na fronteira entre o Brasil e a Guiana Inglesa, apenas campanhas esporádicas de evangelização, frutos das comunidades eclesiásticas localizadas em Geogetown. Houve também casos isolados de índios Makuxi [...] que aderiram ao cristianismo pelo curto convívio com as antigas missões anglicanas do século XIX, bem como igrejas da mesma denominação, localizadas nas vilas, pequenas cidades e na capital Georgetown (Souza, 2006, p. 19-20).
\end{abstract}

$\mathrm{O}$ acesso dos viajantes às áreas fronteiriças onde circulavam os povos Waiwai se dava, geralmente, a partir do Norte em direção ao Sul, ou seja, pela Guiana e não pelo Brasil. Isso era possível devido às relações internacionais da Guiana com os Estados Unidos, uma vez que este país é de colonização inglesa. No entanto, Howard (2001) observa que a convivência mais frequente dos povos Waiwai com os não indígenas (Karaywa) vai se intensificar a partir dos anos de 1950, quando os missionários norte-americanos (evangélicos) passam a se instalar às margens do alto rio Essequibo, na Guiana. Nesta relação, é possível perceber mecanismos de controle e de exploração que denunciam a continuidade das formas coloniais de dominação social, material e intersubjetiva, marcantes nas estruturas de poder e nos modos de ser e saber dos países latino-americanos (Quijano, 2005). Em face disto, a perspectiva decolonial se apresenta como uma possibilidade de reescritura das histórias silenciadas, das subjetividades negadas e dos conhecimentos subalternizados pela racionalidade moderna (Escobar, 2005), face fundante da colonialidade.

Caixeta de Queiroz (2015) explica que a primeira frente evangélica entre os Waiwai ocorreu pelas mãos dos irmãos Hawkins (Rader, Neil e Robert Hawkin) e por Claude Leavitt, este último chamado pelos indígenas de Kron. Esses missionários já atuavam na região desde 1945, mas resolveram se estabelecer entre os Tarumã-Parukoto por volta de 1949- 
1950 (Caixeta de Queiroz, 2015). Ewká, um dos xamãs mais importantes para os Waiwai, foi o primeiro indígena a ser convertido, pelas estratégias missionárias, ao cristianismo evangélico.

Todavia, Schuler Zea (2010), pesquisadora do departamento de antropologia da Universidade Federal de Santa Catarina (UFSC), chama atenção para as relações entre os Waiwai e os missionários, pois, para esta autora, elas vão ocorrer em diversos âmbitos, "[...] por isso este processo não deveria ser simplesmente chamado de 'conversão' ao Cristianismo, mas visto no contexto de uma complexa rede de relações com diversos outros, fundamentais para a constituição do coletivo Waiwai” (Schuler Zea, 2010, p. 8).

Nas páginas iniciais da obra Christ's witch doctor ${ }^{9}$, Dowdy (1997) se utiliza de "[...] um discurso místico-religioso e doutrinador" para narrar, em tom de pacificação, a introdução de novas regras morais religiosas entre os Waiwai (Câncio; Araújo, 2018). No trecho a seguir podemos verificar como foi tramada essa inserção e a expectativa missionária de conversão dos indígenas:

\begin{abstract}
[...] os missionários concluíram que, se quisessem ganhar o povo, teriam de começar alcançando os homens e, por meio deles, as mulheres e as crianças. A prova de estar certo, este meio diferente de aproximação, veio muitas vezes nos meses seguintes, a começar com a conversão do mais improvável homem da tribo [Ewká]. Esta e outras intervenções - algumas reconhecidas apenas tardiamente com a direção de Deus - vieram pela oração. Um homem começou a orar pelos uai-uais em 1926, quando, para o mundo, essa tribo era somente um nome alistado nos jornais embolorados dos exploradores do século dezenove. Ajudar a revelar o poder de Deus a esse povo foi preocupação de cristãos na América, Grã-Bretanha e outros lugares - a de parentes, amigos pessoais, igrejas de origem dos missionários e suas entidades mantenedoras, e da Missão Evangélica da Amazônia [...] (Dowdy, 1997, p. 10).
\end{abstract}

Sabendo que não haveria possibilidade de conversão às novas regras se condutas fossem impostas, logo os missionários deduziram que a transformação dos indígenas em cristãos não teria sucesso se todo o grupo não fosse dominado a ponto de incorporar no cotidiano da vida a moral cristã, objetivo político de controle e subjugação do projeto missionário. Diferente das práticas comuns de conversão entre os povos indígenas, os missionários passaram a investir num plano estratégico de atingir a todos a partir da aceitação de Cristo pelo Ewká, principal xamã e líder espiritual dos Waiwai. Esse processo sempre era iniciado com orações e, da mesma forma que os missionários, Ewká, uma vez convertido, assumia o mesmo comportamento dos missionários, como utilizar o quadro negro para ensinar o alfabeto e os novos conhecimentos sobre o deus cristão aos demais indígenas (Dowdy, 1997).

No que se refere a um processo mais efetivo de escolarização dos conhecimentos dos norte-americanos entre os Waiwai, Souza (2014) ob- 
Dominação e Resistência na Escolarização Cristianizada na Amazônia

serva que os missionários tinham urgência em colocar o papel de Deus no idioma waiwai,

[...] pois a crença em Kaan se apoiaria na crença do Livro, e as representações e condutas WaiWai seriam fundamentadas no ensino do Papel de Deus. Histórias bíblicas do Antigo Testamento foram traduzidas para reforçar as noções da teologia cristã 'tornando-se um espelho no qual os WaiWai poderiam ver a si mesmos' [...] reforçando as concepções sobre criação, pecado, Cristo. O interesse pelas histórias fez crescer o desejo de muitos WaiWai em dominar a arte de fazer o papel falar. Além das histórias, músicas serviam paralelamente para a evangelização e o reforço dos dogmas cristãos (Souza, 2014, p. 79).

Dessa relação e contato, que se deu entre dominação e resistência, resultou um entre-lugar, a partir das diferenças (Bhabha, 2013) entre os indígenas e os missionários evangélicos. Na Aldeia Waiwai é possível verificar que o deus Waiwai possui aspectos relacionados à fé cristã, mas também apresenta fortes elementos da cultura ancestral indígena, um exemplo disso é que esse deus é grafado com uma palavra criada pelos próprios indígenas - Kaan.

Outro aspecto que merece ser destacado é que os pastores Waiwai pregam a Bíblia na língua waiwai e estão sempre caracterizados com elementos de sua cultura ancestral nas cerimônias. Nas conversas com os indígenas na Aldeia Mapuera verificamos que muitos de seus mitos sobrevivem em suas memórias e são expressos em suas falas em situações do dia a dia, assim como nos rituais xamânicos de cura, mesmo que estes sejam hoje marginalizados por força do fundamentalismo religioso pregado pelos norte-americanos (Câncio; Araújo, 2018, p. 51).

Nesse jogo de forças sociais entre culturas diferentes, sempre mediado por conflitos, os sistemas de valores e verdades se relativizavam, muitas vezes eram questionados e se sobrepunham. A cultura de quem detinha certos instrumentos de controle, como o conhecimento da língua de quem se desejava converter, possuía uma maior tendência a se sobrepor, dado que detinha um "[...]conjunto de mecanismos de controle - planos, receitas, regras - para governar o comportamento e o homem como dependente de tais mecanismos" (Geertz, 2001, p. 32-33).

Para que os missionários norte-americanos pudessem disseminar suas ideologias entre os Waiwai, eles descreveram, estudaram e sistematizaram a língua indígena para depois ensiná-la na forma escrita. Depois disso, com o intuito de que conhecessem o cristianismo, traduziram a Bíblia para a língua waiwai, trabalho efetivado pelos irmãos Hawkins ${ }^{10}$. Dentre outros, alguns ensinamentos dos missionários podem ser conferidos no trecho a seguir:

[...] perdoar uns aos outros ao invés de praticar feitiçaria, ser paciente e misericordioso com os outros, vencer o hábito de mentir e roubar, ter o comportamento sexual adequado. Os índios com mais de uma esposa foram aconselhados a liberar todas, exceto uma. Essa estratégia 
também visava promover novos casamentos, pois o número de homens disponíveis era maior que o número de mulheres. Cada lição era repetida pelos missionários em outras reuniões da semana, e durante várias semanas, até que o assunto fosse bem memorizado pelos índios. Em algum tempo, a própria liderança nativa teria 'desaconselhado' a realização de danças noturnas, por levarem à prática de relações sexuais fora do casamento, e decidido começar todas as reuniões festivas da aldeia com um ensinamento bíblico (Dowdy, 1997, p. 214).

Em relação aos rituais praticados pelos Waiwai, Fock (1963) relata que antes da inserção dos missionários, duas festividades coletivas de maior expressão das culturas Waiwai, Shodewika e Yamo, eram realizadas. A primeira ocorria quando uma aldeia Waiwai visitava a outra; a segunda, quando os Waiwai evocavam os espíritos da fertilidade por meio de uma dança na qual apareciam mascarados e ficavam na aldeia por vários meses, realizando danças secretas ligadas à anaconda. Schuler Zea (2010) observa que em ambos os festejos o mito Shodewika, narrado em Fock (1963), conta como um casal Waiwai, convidado pelos animais gente ${ }^{11}$, foi e chegou numa festa. Complementa a autora que "[...] os Waiwai não apenas se referem ao mito Shodewika, mas também dão continuação a certos aspectos dos festivais Shodewika, como aquele presenciado por Fock nos anos 50" (Schuler Zea, 2010, p. 10).

Souza (2006) explica que a festa conhecida como Shodewika relacionava humanos e animais. Segundo ele, sua origem está no mito de um herói de mesmo nome que estabelece os níveis de contato entre os Waiwai e os povos animais. Esse "[...] ritual contava com a presença de hóspedes pertencentes a tribos-animais para que se dessem em casamento e para que o processo de Waiwaização pudesse ocorrer" (Souza, 2006, p. 8). Durante a festa havia fartura de comida e bebida na aldeia e algumas pessoas se fantasiavam de animais para encenar a caçada e a valentia dos caçadores. Ainda é possível evidenciar marcas culturais dessas festas nas comemorações cristãs de Natal e Páscoa, nas quais também é festejado o êxito nas caçadas.

Por sua vez, Howard (1993, p. 237) chama atenção para o ritual Pawana, criado, segundo a autora, em meados dos anos setenta para encenar a chegada de visitantes que viviam mais distantes, sejam eles humanos ou não. Ela explica que,

Os preparativos para o ritual começam com seis semanas de antecedência, quando se escolhem os patronos; este tempo é dedicado à acumulação de grandes reservas de beiju e tapioca, bem como a empresas coletivas de reparo dos terrenos públicos e de produção de cestaria, cerâmica, flechas e esculturas de madeira, esforços que culminam, nos últimos dez dias, em uma caçada coletiva levada a cabo pelos homens (Howard, 1993, p. 241).

Trata-se de um ritual, entre outros, que ocorre durante os festivais que duram cerca de uma semana e são organizados atualmente 
Dominação e Resistência na Escolarização Cristianizada na Amazônia

para acontecer no período do Natal e da Páscoa. É um evento no qual os Waiwai dramatizam seus princípios organizadores a partir da concepção de totalidade, que supera um pensamento pautado em unidades menores de produção e consumo. Segundo Howard (1993), no ritual Pawana estão envolvidos aspectos de festas de outros povos indígenas, assim como aspectos da tradição cristã, como os banquetes, as danças, as trocas cerimoniais e as lutas, estas introduzidas na relação com os estrangeiros.

Uma questão interessante destacada por essa mesma autora sobre este ritual é a encenação de situações comuns nos históricos confrontos culturais vivenciados pelos Waiwai no processo de interação com os não indígenas no extenso território fronteiriço do Brasil. Em suas imitações eles encenam alguns comportamentos dos visitantes. Sempre utilizam nesse ritual algum adereço que identifique o outro, diferente de nós, o qual passa a ser submetido no ritual a situações cômicas (Howard, 1993, p. 260). Nessas imitações os Waiwai fazem pouco uso da linguagem verbal, sendo a expressão corporal o principal meio de comunicação. Pela imitação do outro eles experimentam novas perspectivas, novos diálogos, uma nova maneira de se relacionar e de vivenciar as coisas, observa a autora.

Encenar gestos comportamentais do outro implica conhecer outras perspectivas, outras maneiras de ser, e essa possibilidade é explorada pelos Waiwai na escolha das imitações, que estão para além da repetição e da semelhança, já que eles estão mais interessados em marcar a diferença. Trata-se, portanto, não de uma imitação fiel do outro, mas de uma caricatura que os leve a situações engraçadas, como destacado por Howard (1993).

É importante destacar nesse ritual atitudes que remetem ao controle dos Waiwai, da apropriação e da manipulação que eles fazem dos recursos trazidos pelos visitantes, e isso vai ocorrer em meio a um jogo de atração, persuasão e sedução na relação Waiwai com os não indígenas (Howard, 1993). Nessas encenações, os Pawana, visitantes, “[...] desprezam as oferendas dos 'Waiwai', mostram cobiça ao insistirem em pagamentos mais elevados, afobam-se nas negociações, acusam seus parceiros comerciais ‘waiwai' de serem avaros” (Howard, 1993, p. 246).

Para Howard (1993), embora a improvisação “[...] se faça em meio ao riso e à algazarra, sendo definida como 'brincadeira' e 'farsa', ela toca em cordas sensíveis da cultura 'séria’”, pois, para a autora, esse processo de construção da alegria também expressa uma forma de construção da sociedade. Howard (1993, p. 238) destaca que a encenação jocosa da chegada imaginária dos visitantes evidencia a continuidade "[...] do impulso para encenar os princípios de produção e reprodução desta sociedade, sob as novas condições impostas pelo contato com o Ocidente". Dias Jr. (2005), por sua vez, considera que essas encenações contrárias marcam uma diferença, demonstram como se constrói a alteridade entre eles, e se revelam como uma maneira de reformular e renovar as posições e relações estabelecidas naquele contexto. 
Howard (1993) compreende que o outro para os Waiwai é um desafio a ser enfrentado, não algo a ser evitado. Que eles entendem que por meio dessa relação há uma possibilidade deles mostrarem as suas habilidades de persuasão, uma vez que esse outro também pode possuir recursos e poderes atrativos para eles; que acenam para a histórica troca de recursos materiais e imateriais entre os sujeitos. É importante observar que muitas danças e ciclos festivos foram transformados pelos Waiwai em eventos comuns, mas tais eventos são sempre carregados de simbolismos da cosmologia indígena, o que marca uma posição de resistência. Isso demonstra que nas relações de troca não ocorreu somente um processo de apropriação de outras culturas, mas, sobretudo, de hibridização e ressignificação dos rituais ancestrais.

O conhecimento dos desdobramentos de alguns aspectos dos rituais praticados pelos Waiwai nesse processo de contato com o estrangeiro é importante para entendermos que a escolarização cristianizada promovida pelos missionários norte-americanos não envolve apenas questões relativas ao processo de ensino-aprendizagem da língua indígena, mas também a disseminação de um conjunto de ideologias cristãs que buscaram interferir de forma profunda na cultura indígena, o que vai ocorrer num contexto de disputas que se prolongam até hoje. Essa forma de colonialidade do Ser está muito relacionada à não existência e à desumanização dos sujeitos (Walsh, 2007), uma vez que para os missionários os indígenas precisavam de salvação porque viviam no pecado, eram incapazes de pensar e de construir a própria história, argumentos utilizados para justificar a imposição da moral e da ética cristã.

Nesse jogo de forças sociais, a língua indígena aprendida pelos missionários não foi utilizada apenas como um veículo de transmissão de informação, ela foi utilizada, sobretudo, como um instrumento de poder que visava subestimar e transformar a cultura do outro. De posse dos conhecimentos grafados na língua indígena, eles trabalharam para legitimar esses conhecimentos, uma vez que seria contraditório não os validar, já que foram ensinados com rigor metódico ${ }^{12}$.

De forma mais sistematizada, já que boa parte dos indígenas adultos já detinham o conhecimento da escrita e da leitura de sua própria língua, os missionários passaram a ensinar a escrita Waiwai também para as crianças na escola. Nesta direção, eles treinaram alguns alunos para serem monitores. Embora tenha chegado entre os Waiwai em 1974, foi somente a partir de 1976 que a missionária Irene Benson começou a ensinar as crianças a ler e a escrever na escola. Nessa época foram indicados quatro monitores indígenas para trabalhar com ela, os quais já detinham certo domínio da leitura e escrita Waiwai.

A missionária então deu início a um processo de alfabetização que levava as crianças a ler e estudar a Bíblia. Esse processo de ensino durava até a $4^{\text {a }}$ série ( $5^{\circ}$ ano). Quando os alunos chegavam a esta última série, eles a repetiam nos anos seguintes, já que a continuidade dos estudos lhes era negada. Os indígenas professores dizem como isso ocorria: 
Dominação e Resistência na Escolarização Cristianizada na Amazônia

[...] eu comecei a estudar com ela [irmã Irene]. Eu estudava na escola, mas na escola a gente estudava somente na língua Waiwai a alfabetização. [...] ela aprendeu a falar também a nossa língua [...] (Relato do INDPROF 6, 22/11/2016).

Foi ela [irmã Irene] que nos ensinou a nossa língua, produziu e também ajudou a produzir alguns materiais escritos sobre a nossa língua indígena. E era esse material que nos ajudava a aprender a ler a Bíblia (Relato do INDPROF $2,16 / 11 / 2016)$

O livro, a escrita e a leitura fundamentados no protestantismo tornam-se a expressão mais forte da cultura ocidental naquele contexto. O papel da escrita, nesse processo, é um elemento que se articula simbolicamente às práticas sociais, impondo a grafia sobre aquele que se vê como ágrafo. Os missionários, por dominarem a leitura e escrita, acabaram por ser considerados senhores de uma religião superior. Eles reuniam os instrumentos necessários para persuadir ou forçar os sujeitos a abandonarem um conjunto de crenças e práticas para adotarem novos conhecimentos com os registros da cultura ocidental, como o cristianismo, o que vai se desenvolver em meio a embates e resistências. À luz da decolonialidade, a moral cristã, base desse processo, se configura em uma forma de violência epistêmica e o discurso político/ científico, conforme entende Quijano (2005), passa a ser utilizado pelos missionários norte-americanos para marcar uma diferença hierárquica entre eles e os Waiwai e também para provocar o silenciamento e o esquecimento dos valores e práticas indígenas.

A introdução da escrita entre o povo Waiwai pelos missionários evangélicos teve a Bíblia como instrumento principal, a qual passou a ser, por muitos anos, o único texto lido na Aldeia Mapuera, já que a leitura se sobrepunha à escrita, dada a pretensão da conversão religiosa. Nesse processo, dois mundos aparentemente distantes - o dos missionários e o dos indígenas - se entrecruzaram numa relação de poder que se manifestava contra os indígenas, principalmente por conta da demonização e da negação de seus conhecimentos. Tudo que não se enquadrava nos padrões religiosos e morais definidos pelo cristianismo era considerado pelos missionários fora do padrão de humanidade e civilidade, e era, portanto, combatido.

Convencida da necessidade de evangelizar os Waiwai, a missionária utilizou a língua indígena para escolarizar os seus conhecimentos, tornando a cultura ocidental presente naquele contexto. Ela faz com que o discurso da cristianização, que antes era estranho para os indígenas, se torne familiar, adquirindo sentido entre eles. Esse processo se dava no dia a dia e uma das estratégias utilizadas para evitar o contato dos indígenas com outros grupos, de modo a não colocar em risco o projeto de dominação pela conversão, era a de os manter sob controle, por meio dos conhecimentos ensinados no processo de aprendizado da escrita. Um indígena relata como a missionária operava:

Ela não nos ensinou o inglês, a língua dela. Ela dizia que iria ensinar somente a língua indígena na escola, que a 
gente devia aprender somente Waiwai, e que a gente precisava aprender somente para ler a Bíblia. Mas, depois, outro cacique disse que nós deveríamos aprender pelo menos duas línguas. Aí foi que tudo mudou de novo. Irmã Irene dizia que ela não queria desvalorizar a nossa aldeia. Ela era antropóloga, por isso que não queria nos desvalorizar (Relato do IND2, 25/11/2016).

No que se refere ao movimento de insubordinação linguística, que vai se manifestar nas estratégias de fuga para a cidade, quando os indígenas transgridem as regras impostas pelos missionários, podemos dizer que os Waiwai eram motivados pelo desejo de estabelecer contato com os falantes de português e isso exigiu deles conhecimentos e apropriação dessa nova língua. Esse desejo os levava a romper as regras impostas e a investir em expedições para as cidades, criando estratégias para adentrar o contexto não indígena. No trecho a seguir, um professor aborda uma de suas expedições à cidade:

Ele disse que iria mandar verificar se estávamos embarcando pra cidade. E falou: vocês estão embarcando pra cidade sem nenhuma autorização. [...] Mas dissemos pra nós mesmos que a gente precisava ir de qualquer maneira. [...] Dois de nossos amigos então sugeriram que voltássemos amanhã. Eu não gostei quando eles disseram isso e falei: não, eu não vou voltar! (Relato do INDPROF $1,27 / 06 / 2016)$.

O projeto expansivo de cristianização Waiwai buscava a subalternização do outro para o fortalecimento de uma ideologia que também vai se manifestar na visão que o indígena passa a construir de si a partir do contato com o não indígena. Numa clara atitude contra-hegemônica e de resistência, tal questão também pode ser evidenciada na fala desse mesmo professor ao refletir sobre a imagem negativa que as sociedades hegemônicas têm dos indígenas quando estes não conseguem se comunicar na língua portuguesa:

Se eu não soubesse falar nem escrever em português, seria tudo muito mais difícil. É como se eu não soubesse de nada, como se eu fosse um analfabeto. A minha situação ficaria muito prejudicada, porque se nós não soubermos falar o português, assim como a língua indígena, nós vamos sofrer mais preconceitos, porque as pessoas pensam que nós não temos conhecimentos (Relato do INDPROF 1, 27/06/2016)

Neste caso, verificamos que o INDPROF 1, por ter aprendido a língua portuguesa, não se submeteu ao controle do discurso, nem do contexto. O controle do contexto pode ocorrer, segundo Van Dijk (2015), quando nos eventos comunicativos, que não consistem somente na escrita e na fala verbal, há uma tentativa de monitoramento da situação que influencia o discurso. Assim, podemos dizer que o poder de influência exercido por determinado grupo social sempre está relacionado ao acesso a certos recursos materiais que ele possa ter ou que lhes 
Dominação e Resistência na Escolarização Cristianizada na Amazônia

possam ser proporcionados por outros grupos. No caso das formas de colonialidade não se trata somente de capital ou do território, ou da apropriação de recursos materiais, mas também da posse de recursos simbólicos, tais como o conhecimento (Van Dijk, 2015).

Mesmo que os missionários norte-americanos utilizassem como argumento de defesa o trabalho missionário entre os indígenas, sempre houve especulação entre eles que os norte-americanos também tinham interesse nas riquezas minerais da floresta, questão que é silenciada na Aldeia Mapuera. A missão de disciplinar e organizar a população indígena sempre foi vista com desconfiança pelos próprios indígenas naquele contexto. E isso despertava neles outros interesses, principalmente a vontade de conhecer o lugar de onde vinham os outros, os que não pertenciam àquele território. E esse desejo fez com que alguns Waiwai fossem levados aos Estados Unidos. Um professor expressou essa vontade de conhecer o lugar de onde vinham aqueles que tentavam impedi-lo de atravessar para outros territórios não indígenas:

Em 1981 havia uma firma, eles chegaram na aldeia por conta disso. Aí eu tive uma ideia. Poxa, seria interessante eu conhecer o lugar de onde eles vinham. Mas na minha infância tinha uma norma, Cacique Ewká não deixava jovem sair pra cidade. Havia uma norma que era sustentada pelos missionários na aldeia. Era muito raro alguém sair da aldeia para a cidade. Entre os colegas, eu sabia que precisava ir pra cidade (Relato do INDPROF 1, 27/06/2016).

Há, portanto, um exercício de poder tutelar que deve ser pensado em relação à invasão de territórios indígenas, principalmente no que diz respeito ao processo de domínio exercido em uma única direção. Se, por um lado, os missionários se sentiam à vontade para adentrar o território Waiwai, o mesmo não era permitido a eles, ou seja, o de adentrar o território não indígena do lado brasileiro. Nessas relações, o que está explícito é que as sociedades hegemônicas, de maior poder de domínio, impõe ao outro, como no caso dos Waiwai, práticas disciplinares articuladas a estratégias e táticas enunciativas que o impede de exercer, em direção contrária, os mesmos esquemas e processos. Isso só é possível por meio de embates e resistências.

A tentativa da missionária de impedir que outros conhecimentos fossem apreendidos pelos indígenas, como, por exemplo, o aprendizado da língua portuguesa, ainda que eles estivessem em território brasileiro, é uma demonstração de poder e de tentativas de controle exercidos sobre os Waiwai. Esta forma de controle é relatada pelo professor indígena a seguir:

Nós aprendemos no dia a dia a língua indígena [...] Irmã Irene nos ensinou a escrever em Waiwai [...] Ela só nos ensinava Waiwai e bem pouco de português, ajudava fazer alguma tradução de Waiwai para português e de português para Waiwai (Relato do INDPROF 5, 24/11/2016). 
A base de todo processo de ensino da escrita e da leitura Waiwai era a perfeição humana, fundamentada no texto bíblico. O discurso de ordem era a obediência absoluta às escrituras, que se efetivava em meio a um jogo de lutas hegemônicas, forjadas para legitimar o saber ocidental, esconder e negar os conhecimentos indígenas. É desse processo de superposição da epistemologia ocidental, pautado na ideia de universalidade, que são negados aos povos situados em contextos históricos específicos as suas próprias epistemologias (Mignolo, 2006). E é desse silenciamento das epistemologias indígenas que resultarão, por exemplo, as narrativas de transição, hierarquizadoras das sociedades em modernas e tradicionais (Mignolo, 2003).

Entre os argumentos usados pelos missionários, havia aqueles que eram respaldados num padrão ideal de ser (Câncio; Araújo, 2018, p. 50), já que os indígenas eram vistos como sujeitos corroídos pelos pecados, como expresso no seguinte trecho da obra de Dowdy: “[...] vocês precisam abandonar seus pecados. Amem a Jesus e não ao pecado. Não nos imitem; imitem a Deus. Não sejam preguiçosos em ouvir o Papel de Deus" (Dowdy, 1997, p. 239).

Nessa obra, Dowdy (1997) destaca que ao apresentarem Jesus Cristo aos Waiwai os missionários não se importavam “[...] em impor os arreios da cultura ocidental aos índios cujas selvas, rios e maneira de vestir, serviam muito bem às suas necessidades". Ou seja, mesmo cientes dos conhecimentos ancestrais dos povos Waiwai, por meio da escolarização cristianizada, os missionários investiram em estratégias para subvertê-los e impor conhecimentos outros, mediante a comparação entre as culturas. E isso pode ser verificado neste trecho da narrativa da missionária sobre como ocorria a pregação do evangelho entre os Waiwai:

O ensino de Bam enfatizava os contrastes do mundo espiritual. - Jesus morreu na cruz para destruir os maus espíritos. Jesus cortou as amarras e anulou o poder dos tabus. Se fez isso, como poderia Ele conviver ao lado dos maus espíritos dentro de você? Você precisa escolher entre Jesus e os espíritos (Dowdy, 1997, p. 169).

A nova religião, guiada por um livro, faz do aprendizado da leitura e da escrita o principal meio para a evangelização e o ensino dos dogmas cristãos o elemento principal para a consolidação de uma lógica religiosa ocidental híbrida entre os indígenas, pois os elementos da cultura Waiwai permanecem cravados nos eventos religiosos cristãos e em reuniões na Aldeia Mapuera (Câncio, 2017).

É, portanto, dessa histórica articulação das diferenças culturais que se constituiu o conhecimento escolar em Mapuera. O cristianismo não trouxe a eles apenas um novo saber espiritual, mas uma nova tecnologia, materializada no livro, na escrita e na leitura, que tinha nas escrituras sagradas, com todo o seu teor cultural e ideológico, o processo de conversão. Entre o conhecimento dos espíritos ancestrais e a palavra do Deus cristão, já de posse do domínio da escrita e da leitura, 
Dominação e Resistência na Escolarização Cristianizada na Amazônia

os Waiwai passam a ressignificar e a refletir sobre as suas identidades ao reconhecerem uma nova autoridade: a dos escritos do texto sagrado.

\section{Considerações finais}

Verificamos neste estudo que, no contexto da realidade latinoamericana, a Amazônia brasileira é marcada por históricas resistências e combates às muitas formas de colonialidade produzidas pelos agentes do poder capitalista. As estratégias de cristianização indígena, promovidas pelos missionários, agentes importantes da colonização na Amazônia, alcançaram os Waiwai e ocorreram no rastro desse modelo de poder ao serem submetidos a práticas de colonialidade do ser e do saber, recursos utilizados para disseminação e afirmação de conhecimentos que mobilizaram valores e ideologias contrapostos a outras formas epistêmicas de interação dos Waiwai com o mundo.

Pudemos verificar neste estudo que a conversão religiosa fez com que os Waiwai passassem a reavaliar o seu próprio universo cosmológico e espiritual, atribuindo-lhes algumas vezes valores negativos. Mas esse processo de conversão ao cristianismo evangélico não se deu de forma pacífica ou consensual; ele vai ocorrer em meio a uma complexa rede de relações com vários grupos indígenas e entre confrontos, embates, continuidades e descontinuidades, que competiram para formar este espaço de intermédio que é a Aldeia Mapuera. Nesta aldeia há pastores indígenas que pregam a Bíblia na língua waiwai ao mesmo tempo em que expressam elementos marcantes de suas culturas ancestrais. Eles carregam em seus corpos e em seus discursos as contradições vivenciadas e as resistências decorrentes desse processo histórico-social.

Para compreender o processo de escolarização dos conhecimentos dos missionários norte-americanos como estratégia de cristianização indígena, e analisar o movimento de insubordinação social e linguística na introdução da escrita entre o povo Waiwai, foi preciso empreender um vigoroso esforço de entendimento das inter-relações que esses indígenas estabeleceram com os missionários, detentores de maior poder econômico. Compreendemos que os atos de rebeldia contra as estratégias cristianizadoras, arregimentados por procedimentos de coerção e interdição engendrados pelos missionários, ajudaram a fortalecer a identidade Waiwai, o que também favoreceu o reconhecimento de uma posição de autoridade do grupo naquele contexto.

Mesmo com diversas tentativas de silenciamentos dos conhecimentos Waiwai, a escolarização cristianizada se deu entre embates e resistências e vai se desenvolver entre atos de rebeldia contra os dispositivos opressores utilizados. Nesse processo, a leitura da organização social e o conhecimento de alguns aspectos sociolinguísticos Waiwai são importantes porque nos ajudam a entender, inclusive, a construção da lógica religiosa ocidental híbrida atualmente vivenciada pelos indígenas na Aldeia Mapuera. O jogo de lutas hegemônicas, forjadas para negar os conhecimentos indígenas e legitimar o saber ocidental entre os Waiwai, evidencia as estratégias de cristianização e as irrupções em 
torno das condições de produção, circulação e manutenção dos conhecimentos naquele contexto.

Recebido em 11 de agosto de 2020 Aprovado em 14 de dezembro de 2020

\section{Notas}

1 O presente artigo foi baseado na tese de doutorado de Câncio (2017), intitulada "Para Além da Aldeia e da Escola: um estudo decolonial de aquisição da Língua Portuguesa pelos indígenas Waiwai da Aldeia Mapuera, Amazônia brasileira”, defendida no Programa de Pós-graduação em Educação da Universidade Federal do Pará.

2 Com base em Gallois (2004), utilizamos o termo Terra Indígena para nos referirmos ao processo jurídico-político de demarcação conduzido pelo Estado e Território para nos referirmos à construção da vivência, culturalmente variável, da relação entre a sociedade indígena e sua base territorial.

3 Conforme Howard (1993, p. 245), o nome Waiwai está relacionado a Povo da tapioca. A tapioca é, para eles, um alimento de sociabilidade.

4 Para Howard (2001, p. 46), essa diferença de cor entre os Waiwai e os Wapixana se deve à maior exposição destes últimos ao sol, já que eles vivem numa região de savanas, onde a vegetação é baixa, enquanto os Waiwai vivem no meio de uma densa floresta, protegidos pelos raios solares.

5 Tapioca ou beiju são produtos da mandioca preparados por mulheres Waiwai.

6 As falas dos indígenas utilizadas neste estudo são abordadas no estudo de Câncio (2017) sobre a aquisição da língua portuguesa na Aldeia Mapuera-PA.

7 Acácio (2011) realizou estudo sobre os aspectos fonológicos da língua waiwai, o qual resultou na sua Dissertação de Mestrado em Letras pela UFPA.

8 A colonialidade também implica relações internacionais de poder e internas, dentro dos países, o que na América Latina tem sido denominado como dependência histórico-estrutural (Quijano, 2007).

9 O jornalista Homer Dowdy visitou as aldeias na Guiana, por volta de 1960. Nessa obra, ele narra o processo de conversão dos Waiwai ao cristianismo evangélico. Publicada em 1963, nos Estados Unidos, a obra aborda a trajetória de Ewká, primeiro Waiwai indígena a seguiros ensinamentos dos missionários e o primeiro a se tornar pastor.

10 Os Hawkins possuíam treinamento em linguística e desde os primeiros contatos com os Waiwai anotavam o máximo de palavras indígenas que conseguiam nas aldeias (Dowdy, 1997).

11 Os animais gente, segundo Schuler Zea (2010, p. 10), eram humanos nos tempos míticos, "[...] tinham a aparência de humanos, mas nas festas usavam roupas de animais como vestimentas de dança".

$12 \mathrm{Na}$ história de muitas culturas ágrafas a escrita foi utilizada para impor e estabelecer uma forma de falar, de escrever e de pensar, o que sempre ocorre por meio de disputas e embates. 
Dominação e Resistência na Escolarização Cristianizada na Amazônia

\section{Referências}

ACÁCIO, Mara Silvia Jucá. Estudo Fonológico da Língua Waiwái (Caribe): uma contribuição. 2011. 118 f. Dissertação (Mestrado em Letras) - Programa de PósGraduação em Letras da Universidade Federal do Pará, Belém, 2011.

ANDRÉ, Marli Eliza Dalmazo Afonse de. Estudo de Caso em Pesquisa e Avaliação Educacional. Brasília: Líber Livro, 2008.

BHABHA, Homi. O Local da Cultura. Belo Horizonte: UFMG, 2013.

CAIXETA DE QUEIROZ, Ruben. Cosmologia e História Waiwai e Katxuyana: sobre os movimentos de fusão e dispersão dos povos (yana). In: GRUPIONI, Denise Fajardo; ANDRADE, Lúcia Mendonça Morato de. Entre Águas Bravas e Mansas: índios \& quilombolas em Oriximiná. São Paulo: Comissão Pró-Índio de São Paulo: Iepé, 2015. P. 104-133

CÂNCIO, Raimundo Nonato de Pádua. Para Além da Aldeia e da Escola: um estudo decolonial de aquisição da Língua Portuguesa pelos indígenas Waiwai da Aldeia Mapuera, Amazônia brasileira. 2017. 275 f. Tese de Doutorado (Doutorado em Educação) - Universidade Federal do Pará, Belém, 2017.

CÂNCIO, Raimundo Nonato de Pádua; ARAÚJO, Sônia Maria da Silva. Violência Epistêmica e a Invenção do outro na Narrativa 'O Pajé de Cristo', de Homer Dowdy. Tellus, Campo Grande, MS, ano 18, n. 37, p. 39-57, set./dez. 2018.

DIAS JUNIOR, Carlos Machado.Trajetórias e Construções Sociais entre os Povos. Tellus, Campo Grande, ano 8, n. 15, p. 59-82, jul./dez. 2005.

DOWDY, Homer. O Pajé de Cristo: uma história do amor de Deus operando milagres nas selvas da Amazônia. Título original: Christ's Witch Doctor. New York: Harper; Row, 1963. Trad. Fausto Camargo César. São Paulo: Editora Sepal, 1997.

ESCOBAR, Arturo. Mas allá del Tercer Mundo. Globalización y Diferencia. Bogotá: Instituto Colombiano de Antropología e Historia, 2005.

FOCK, Niels. Waiwai: religionand society of na Amazonian tribe. Copenhagen: The National Museum, 1963.

FRIKEL, Protásio. Classificação Lingüístico-Etnológica das Tribus Indígenas do Pará Setentrional e Zonas Adjacentes. Revista de Antropologia, São Paulo, n. 6, p. 113-188, 1958.

GALLOIS, Dominique Tilkin. Terras ocupadas? Territórios? Territorialidades?. In: RICARDO, Fany (Org.). Terras Indígenas \& Unidades de Conservação da Natureza. São Paulo: Instituto Socioambiental, 2004. P. 37-41.

GEERTZ, Clifford. A Interpretação das Culturas. Petrópolis: Vozes, 2001.

HAWKINS, Neill W. A Fonologia da Língua Uáiuái. In: Boletin da Faculdade de Filosofia Ciências e Letras. São Paulo, USP, v. 157, n. 25, p. 2-49, 1952.

HAWKINS, Robert E. Wai Wai. In: DERBYSHIRE, Desmond C; PULLUM, Geoffrey K. (Org.). Handbook os Amazon Languages, v. 4. Berlim - New York: Mouton de Gruyter, 1998. P. 25-224.

HOWARD, Catherine Vaughan. Pawana: a farsa dos visitantes entre os Waiwai da Amazônia. In: CASTRO, Eduardo Viveiros de; CUNHA, Manuela Carneiro da. Amazônia. Etnologia e história indígena. São Paulo: NHII/ USP/ FAPESP, 1993.

HOWARD, Catherine Vaughan. A domesticação das mercadorias: estratégias Waiwai. In.: ALBERT, Bruce; RAMOS, Alcidia Rita (Org.). Pacificando os brancos: cosmologias do contato no Norte-Amazônico. São Paulo: UNESP: Imprensa Oficial do Estado, 2001. 
MEIRA, Sérgio. A Família Lingüística Caribe (Karíb). Revista de Estudos e Pesquisas, FUNAI, Brasília, v. 3, n. 1/2, p. 157-174, jul./dez. 2006.

MIGNOLO, Walter. Histórias Globais/Projetos Locais. Colonialidade, saberes subalternos e pensamento limiar. Belo Horizonte: Editora UFMG, 2003.

MIGNOLO, Walter. Os Esplendores e as Misérias da Ciência: colonialidade, geopolítica do conhecimento e pluri-versalidade epistêmica. In: SANTOS, Boaventura de Sousa (Org.). Conhecimento Prudente para uma Vida Decente: 'um discurso sobre as ciências' revisitado. São Paulo: Editora Cortez, 2006. P. 667-771.

QUIJANO, Anibal. Colonialidade do poder, eurocentrismo e América Latina. In: LANDER, Edgardo. A colonialidade do saber: eurocentrismo e ciências sociais perspectivas latino-americanas. Buenos Aires: CLACSO, 2005. P. 107-130.

QUIJANO, Anibal. Colonialidad del Poder y Clasificación Social. In: CASTRO GÓMEZ, Santiago; GROSFOGUEL, Ramón (Org.). El Giro Decolonial: reflexiones para una diversidad epistémica más allá del capitalismo global. Bogotá: Siglo del Hombre Editores, 2007. P. 284-327.

SCHULER ZEA, Evelyn. Redes de Saberes, Circulações e Trocas entre os Waiwai no Brasil e na Guiana: primeiras reflexões a partir de duas viagens transfronteiriças recentes. In: ENCONTRO ANUAL DA ANPOCS, 34., 2010, Caxambu. Anais... Caxambu, 2010. P. 1-17. Disponível em: <https://www.anpocs.com/ index.php/papers-34-encontro/st-8/st28-2/1630-ezea-redes-de-saberes/file > Acesso em: 07 jun. 2020.

SOUZA, Alfredo Ferreira de. Representações WaiWai. 2006. Trabalho apresentado no Programa de pós-graduação de História Social. Rio de Janeiro: IFCS, Universidade Federal do Rio de Janeiro, Rio de Janeiro, 2006.

SOUZA, André Oliveira de. Entre Conversões e Convertidos: táticas e estratégias no encontro cultural entre missionários protestantes e os Waiwai da Amazônia setentrional entre 1948 e 1962. 2014. 116 f. Dissertação (Mestrado em Sociedade e Fronteiras) - Programa de Pós Graduação em Sociedade e Fronteiras da Universidade Federal de Roraima, Boa Vista, 2014.

VAN DIJK, Teun Adrianus. Discurso e Poder. São Paulo: Contexto, 2015.

WALSH, Catherine. Interculturalidad y Colonialidad del Poder. Um pensamiento y posicionamiento 'outro' desde la diferencia colonial. In: GOMEZ, Santiago Castro; GROSFOGUEL, Ramón (Org.). El Giro Decolonial. Reflexiones para uma diversidad epistêmica mas allá del capitalismo global. Bogotá: Siglo del Hombre Editores/Universidad Central/Pontifícia Universidad Javeriana, 2007. P. 47-62.

Raimundo Nonato de Pádua Câncio é professor adjunto da Universidade Federal do Tocantins (UFT). Possui Pós-doutoramento e Doutorado em Educação pela Universidade Federal do Pará (2019); Mestrado em Educação pela Universidade do Estado do Pará (2008). É sócio da Associação Nacional de Pesquisa em Educação (Anped) e docente do Programa de Pós-graduação em Formação Docente em Práticas Educativas/UFMA.

ORCID: http://orcid.org/0000-0002-4791-0269

E-mail: nonato.cancio@uft.edu.br

Sônia Maria da Silva Araújo é professora titular da Universidade Federal do Pará (UFPA). Fez Estágio Pós-doutoral no Centro de Estudos Sociais (CES) da Universidade de Coimbra (2007-2008) e Doutorado em Educação na Universidade de São Paulo (2002). Atuou como vice-presidente Norte da 
ANPEd, biênio 2017-2019. Atua no Programa de Pós-Graduação em Educação da Universidade Federal do Pará.

ORCID: https://orcid.org/0000-0001-8240-9704

E-mail: ecosufpa@hotmail.com

Editora-responsável: Fabiana de Amorim Marcello

Este é um artigo de acesso aberto distribuído sob os termos de uma Licença Creative Commons Atribuição 4.0 Internacional. Disponível em: <http:// creativecommons.org/licenses/by/4.0>. 